\title{
Home-based telerehabilitation: A review of remote therapy frameworks
}

\author{
Telereabilitação domiciliar: Uma revisão dos modelos de terapias à distância \\ Telereabilitación en casa: Una revisión de los modelos de terapia a distancia
}

Received: 04/26/2021 | Reviewed: 05/05/2021 | Accept: 05/06/2021 | Published: 05/20/2021
Guilherme Fernandes de Souza Miguel ORCID: https://orcid.org/0000-0002-7425-1975 Universidade Federal de Uberlândia, Brazil E-mail: guilhermefsmiguel@gmail.com
Angela Abreu Rosa de Sá
ORCID: https://orcid.org/0000-0002-1818-8270 Universidade Federal de Uberlândia, Brazil E-mail: angelaabreu@gmail.com
Júlia Tannús de Souza
ORCID: https://orcid.org/0000-0003-1521-5680 Universidade Federal de Uberlândia, Brazil E-mail julia.tannus95@gmail.com
Eduardo Lázaro Martins Naves
ORCID: https://orcid.org/0000-0003-4175-723X Universidade Federal de Uberlândia, Brazil E-mail: eduardonaves@ufu.br

\begin{abstract}
Remote therapy frameworks play the main role in home-based telerehabilitation. These remote therapies are exergames that help in the physical and cognitive rehabilitation of the patient. The objective of this review is to present the frameworks of home-based therapies using exergames and to identify the points that can be improved in the development of future systems. To carry out this research, the criteria of the PRISMA were adopted. Literature searches were conducted up to April 2021 in the Web of Sicence, Pubmed, Cochrane, Embase and Scopus databases. The search query was: (("game*" OR "exergame*") AND ("rehabilitation") AND ("remote" OR "telerehabilitation" OR "telemedicine")). We have selected a total of fourteen studies. We found five types of frameworks: Client-Server, Web-Based, Layers, Cloud Based and Multi users. We identified that it may be advantageous to mix the features of these frameworks to have a cheaper home-based system and prevent the patient from having to purchase more powerful computers. In addition, there are some challenges that need to be studied that will also help reduce costs for the patient: 1) Reduce the need for high processing of exergames on the patient's computer; 2) Prevent the patient from having to purchase expensive external devices for motion tracking.
\end{abstract}

Keywords: Home-based therapy; Telerehabilitation; Exergames; Remote virtual games.

\section{Resumo}

Os modelos de terapias remotas desempenham o papel principal na telereabilitação domiciliar. Essas terapias remotas são exergames que ajudam na reabilitação física e cognitiva do paciente. O objetivo desta revisão é apresentar os modelos de terapias domiciliares utilizando exergames e identificar os pontos que podem ser melhorados no desenvolvimento de sistemas futuros. Para a realização desta pesquisa, foram adotados os critérios do PRISMA. As pesquisas de literatura foram realizadas até abril de 2021 nas bases de dados Web of Sicence, Pubmed, Cochrane, Embase e Scopus. A consulta da pesquisa foi: (("game*" OR "exergame*") AND ("rehabilitation") AND ("remote" OR "telerehabilitation" OR "telemedicine")). Selecionamos um total de quatorze estudos. Encontramos cinco tipos de frameworks: Cliente-Servidor, Baseado na Web, Baseado em Camadas, Baseado em Nuvem e Multi usuários. Identificamos que pode ser vantajoso misturar as características desses modelos para ter um sistema doméstico mais barato e evitar que o paciente tenha que comprar computadores mais poderosos. Além disso, existem alguns desafios que precisam ser estudados e que também ajudarão a reduzir custos para o paciente: 1) Reduzir a necessidade do alto processamento de exergames no computador do paciente; 2) Evitar que o paciente tenha que comprar dispositivos externos caros para rastreamento de movimento.

Palavras-chave: Terapia domiciliar; Telereabilitação; Exergames; Jogos virtuais remotos.

\section{Resumen}

Los modelos de teleterapia desempeñan el papel principal en la telerrehabilitación a domicilio. Estas terapias remotas son exergames que ayudan en la rehabilitación física y cognitiva del paciente. El objetivo de esta revisión es presentar los modelos de terapias domésticas utilizando exergames e identificar los puntos que se pueden mejorar en el desarrollo de sistemas futuros. Para llevar a cabo esta investigación, se adoptaron los criterios del PRISMA. Las 
búsquedas literarias se llevaron a cabo hasta abril de 2021 en las bases de datos Web de Sicence, Pubmed, Cochrane, Embase y Scopus. La consulta de búsqueda fue: (("game*" OR "exergame*") AND ("rehabilitation") AND ("remote" OR "telerehabilitation" OR "telemedicine")). Hemos seleccionado un total de catorce estudios. Encontramos cinco tipos de modelos: Cliente-Servidor, Basado en Web, Capas, Basado en la Nube y Usuarios múltiples. Identificamos que puede ser ventajoso mezclar las características de estos modelos para tener un sistema doméstico más barato y evitar que el paciente tenga que comprar computadoras más potentes. Además, hay algunos desafíos que deben ser estudiados que también ayudarán a reducir los costos para el paciente: 1) Reducir la necesidad de un alto procesamiento de exerjuegos en el ordenador del paciente; 2) Evitar que el paciente tenga que comprar costosos dispositivos externos para el seguimiento de movimiento.

Palabras clave: Terapia en casa; Telerrehabilitación; Exergames; Juegos virtuales remotos.

\section{Introduction}

Telehealth technologies has a fundamental role in the field of medical and enable the remote monitoring and rehabilitation (Amorim et al., 2020). According to (Mantovani et al., 2020), telerehabilitation approaches have been shown to be effective in patient rehabilitation. This remote rehabilitation allows therapists to perform a remote treatment with a large number of patients from their home, regardless of how far they are from a rehabilitation center.

Moreover, telerehabilitation systems facilitate the monitoring of patients' performance with the evaluation of the medical professional. This makes it easier for therapists to customize rehabilitation exercises for each patient. Through these telererehabilitation systems, therapists can easily follow up patients in a long-term rehabilitation programme. In addition, due to the COVID-19 pandemic, the health system needs telemedicine technologies to enable rehabilitation therapies without patients leaving home (Silva et al., 2021).

In this context, the use of games in telerehabilitation is the best way for patients to perform rehabilitation exercises, using telecommunications resources, in the comfort of home, without having to go to the hospital (Matamala-Gomez et al., 2020). For these therapies via telerehabilitation, serious games or exergames are extremely relevant and applicable. With these types games the patient can replicate the movements that will be presented in the games, which will assist in the rehabilitation process. In addition, exergames provide feedback to the patient about the movement that has been performed, showing whether it is improving or not (Rego et al., 2014). Thus, the exercises assist the therapist by providing information about the patient's performance during rehabilitation sessions, facilitating the follow-up of the patient's evolution. Also, there has been a growing demand for exergames to help patients perform rehabilitation at home (Deponti et al., 2011; Norouzi-Gheidari et al., 2019; Sardi et al., 2017). Home-based technologies have the advantage of allowing patients to choose the place and time they will have rehabilitation therapy and also receive remote monitoring of therapists (Chena et al., 2019).

There are already several telerehabilitation systems in all areas that use exergames. But most of them use the classic Client-Server framework: the Client computer (installed in the patient's home) is responsible for installing, processing and running the game; while the Server computer (usually located in a rehabilitation center) is responsible for storing the patient's rehabilitation program data and information. Thus, the server machine has as main focus the management and reporting regarding patient performance, while the patient's computer is responsible for running the exergame and collecting patient data.

However, although there are already several systems for telerehabilitation, there are challenges in the use of these rehabilitation games at home. One issue is that telerehabilitation systems that use exergames require installation on a computer with high processing power. But, an important point is that user population have different computer configurations: from the simplest (low memory, not so fast processor and simple graphics card) to the most sophisticated.

Despite the constant evolution of exergame systems for rehabilitation, there are still challenges to face, analyze and discuss for future implementations of exergames for home-based telerehabilitation. Thus, this paper aims to review the remote therapy frameworks that use exergames. Our hypothesis is that it is possible to identify solutions to improve home-based telerehabilitation systems and make them cheaper for the patient. 


\section{Methodology}

To conduct the review searches, the criteria for Preferred Reporting Items for Systematic Reviews and Meta-Analyses (PRISMA) were adopted (Moher; et al., 2009).

\section{Study design}

This protocol, which outlines methods for the proposed systematic review, was designed in accordance with PRISMA guidelines. The entire study selection process was carried out by 4 reviewers and summarized in a PRISMA flow diagram (Figure 1).

\section{Inclusion/exclusion criteria}

Eligible articles accounted for studies on remote therapy frameworks using exergames. We excluded studies that only used a remote therapies but did not detail the framework. The research included English and Portuguese language. Data collection took place up to April 2021.

\section{Search sources}

Five databases were consulted: Web of Sicence, Pubmed, Cochrane, Embase and Scopus). For this review, the following query was used: (("game*" OR "exergame*") AND ("rehabilitation") AND ("remote" OR "streaming" OR "telerehabilitation" OR "telemedicine")).

\section{Selection}

Two authors (GFSM and AARS) independently analyzed the titles and abstracts of the studies identified by the research strategy and confirmed the existing duplicates to remove them. Eligible studies were selected after reading the full text to compose this review. Figure 1 depicts the PRISMA flow diagram selection process.

\section{Data collection}

Two authors (GFSM and AARS) extracted data from the selected studies and two others (JT and ELMN) verified and ratified the information. 
Figure 1: PRISMA method used for the selection of articles for this review.
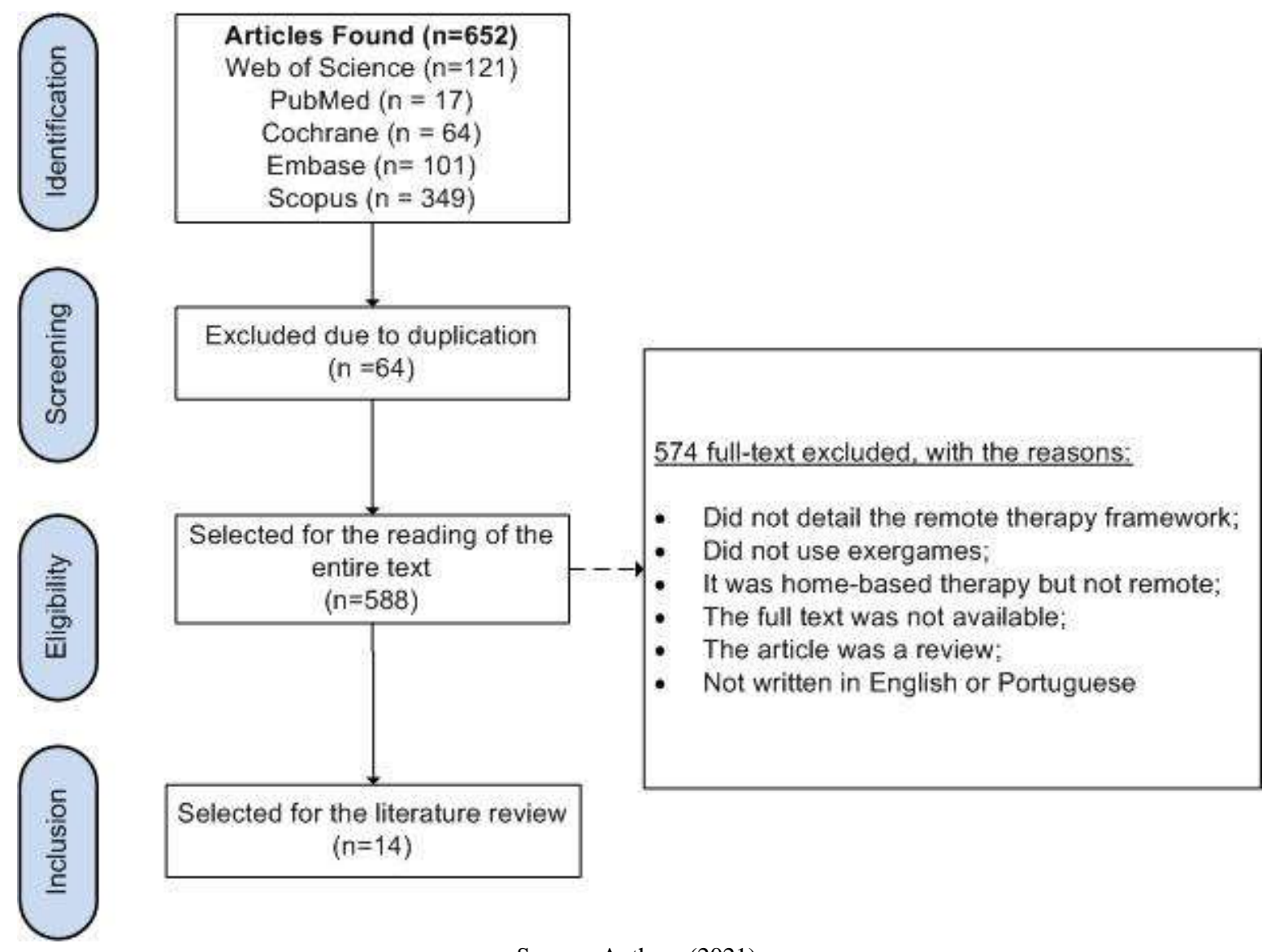

Source: Authors (2021).

\section{Results}

The search in the databases resulted in a total of 652 articles. Duplicated were disregarded and 588 articles remained (Figure 1). After reading the pre-selected studies, 574 were excluded after reading the full text due to the following reasons: 1 ) Did not detail the remote therapy framework; 2) Did not use exergames; 3) It was home-based therapy but not remote; 4) The full text was not available; 5) The article was a review; 6) Not written in English or Portuguese. Therefore, the sample for this review consisted of 14 studies (Figure 1).

The 14 studies selected for this review were published between 2000 and 2021. According to Table 1, we have identified 5 different remote therapy frameworks in the selected studies: Client-Server, Web-Based, Layers, Cloud Based and Multi users. We will discuss each of them in the next session.

Figure 1 presents an overview of the classification of the 14 studies in this review. Among the framework designs of the selected studies, 36\% of them are classified as Web-based (Figure 2.a). In addition, all the studies rely on an external input device to control the exergame, highlighting that $43 \%$ of them use MS Kinect (Microsoft, n.d.) (Figure 2.b). Also, the rehabilitation area of the remote therapies of these studies are diverse, but most (36\%) are applicable in the area of stroke rehabilitation (Figure 2.c). 
Figure 2: Main features of the studies selected in this review: a) Types of remote therapy framework design; b) Models of exergame input devices; c) Rehabilitation area of remote therapy.

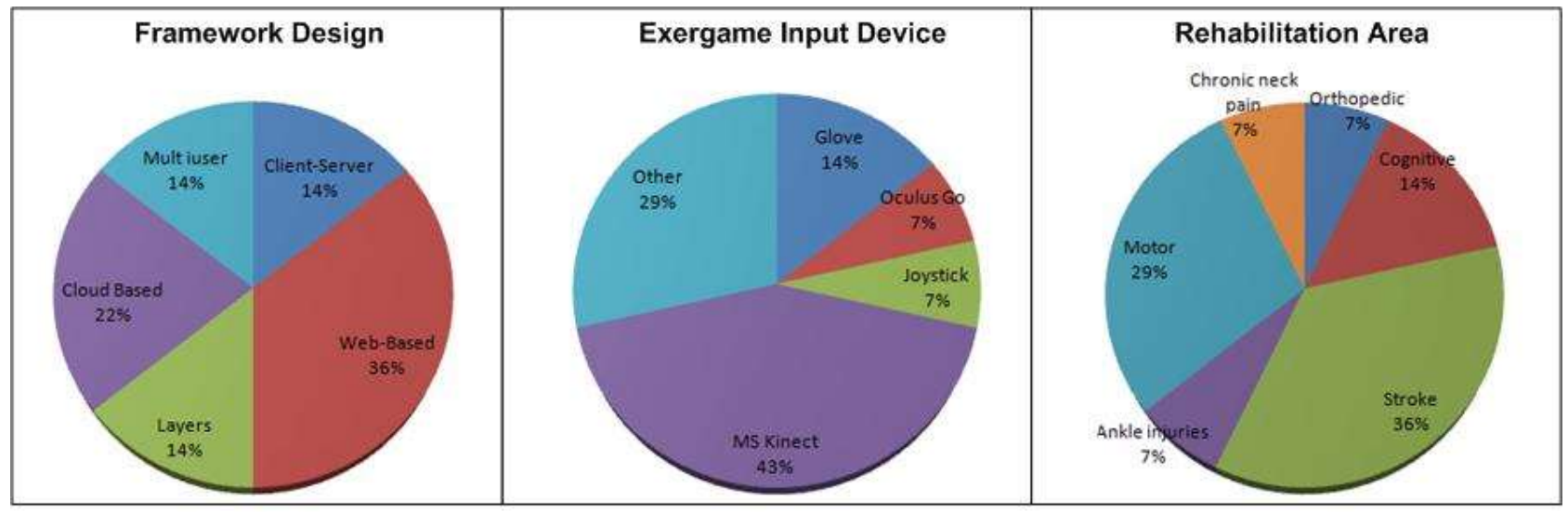

(a)

(b)

(c)

Source: Authors (2021).

Table 1: Remote therapy frameworks selected for this review.

\begin{tabular}{|c|c|c|c|c|}
\hline $\begin{array}{l}\text { Framework } \\
\text { Design }\end{array}$ & Study & $\begin{array}{l}\text { Rehabilitation } \\
\text { Area }\end{array}$ & $\begin{array}{l}\text { Input } \\
\text { Device }\end{array}$ & Highlights \\
\hline Client-Sever & (Popescu et al., 2000) & Orthopedic & Glove & $\begin{array}{l}\text { In addition to recording the patient's } \\
\text { progress, the server side changes the } \\
\text { patient's difficulty level. }\end{array}$ \\
\hline Client-Server & $\begin{array}{l}\text { (Varela-Aldás et al., } \\
\text { 2020) }\end{array}$ & Cognitive & Oculus Go & $\begin{array}{l}\text { Uses an app with a immersive virtual } \\
\text { reality application. }\end{array}$ \\
\hline Web-Based & $\begin{array}{l}\text { (Reinkensmeyer et al., } \\
\text { 2002) }\end{array}$ & Stroke & Joystick & $\begin{array}{l}\text { New versions are automatically } \\
\text { installed each time a user accesses the } \\
\text { therapy web page. }\end{array}$ \\
\hline Web-Based & (Karime et al., 2012) & Ankle injuries & Woblle board & $\begin{array}{l}\text { The system is simple and easy to be } \\
\text { used by people of all ages. }\end{array}$ \\
\hline Web-Based & $\begin{array}{l}\text { (Pérez-Medina et al., } \\
\text { 2019) }\end{array}$ & $\begin{array}{c}\text { Motor } \\
\text { Rehabilitation }\end{array}$ & MS Kinect & $\begin{array}{l}\text { Real time evaluation of the patient } \\
\text { session. }\end{array}$ \\
\hline Web-Based & (Zedda et al., 2020) & Stroke & Inertial sensors & $\begin{array}{l}\text { It allows setting the patient expected } \\
\text { motor skill at any moment. }\end{array}$ \\
\hline Web-based & $\begin{array}{l}\text { (Postolache et al., } \\
\text { 2021) }\end{array}$ & Stroke & Glove & Mobile applications and IoT layers. \\
\hline Layers & $\begin{array}{l}\text { (Vourvopoulos et al., } \\
\text { 2013) }\end{array}$ & Stroke & MS Kinect & $\begin{array}{l}\text { Layers: approach, technology and } \\
\text { implementation. }\end{array}$ \\
\hline Layers & $\begin{array}{l}\text { (Paraskevopoulos et } \\
\text { al., 2016) }\end{array}$ & $\begin{array}{c}\text { Motor } \\
\text { Rehabilitation }\end{array}$ & MS Kinect & Layers: input, game and clinician. \\
\hline Cloud Based & $\begin{array}{l}\text { (H.-J. Li \& Song, } \\
\text { 2017) }\end{array}$ & $\begin{array}{c}\text { Motor } \\
\text { Rehabilitation }\end{array}$ & Robotic Arm & $\begin{array}{l}\text { Cloud robot assisted rhabilitation } \\
\text { system with multimodal interaction. }\end{array}$ \\
\hline Cloud Based & (Afyouni et al., 2020) & Chronic neck pain & MS Kinect & $\begin{array}{l}\text { Back end (analytics and game zones) } \\
\text { and front end (patient and therapist } \\
\text { dashboards) }\end{array}$ \\
\hline Cloud Based & (Oliver et al., 2018) & Cognitive & MS Kinect & $\begin{array}{l}\text { It uses an Inference Subsystem } \\
\text { (artificial intelligence) }\end{array}$ \\
\hline
\end{tabular}




\begin{tabular}{ccccc} 
Multi user & $\begin{array}{c}\text { (Triandafilou et al., } \\
\text { 2018) }\end{array}$ & Stroke & MS Kinect & $\begin{array}{l}\text { A central server interacting with } \\
\text { peripheral client computers. }\end{array}$ \\
Multi user & (Andrade et al., 2013) & $\begin{array}{c}\text { Motor } \\
\text { rehabilitation }\end{array}$ & Orthosis wrist & $\begin{array}{l}\text { Multiple patients integrating robots and } \\
\text { games. }\end{array}$ \\
\hline
\end{tabular}

Source: Authors (2021).

\section{Discussion}

The basic principle of remote therapies of home-based telehabilitation is communication between two computers: a computer that will be installed in the patient's home (Client computer) and another that will be installed in a hospital or rehabilitation center (Server computer) (Bamidis et al., 2015). On the client computer, the exergame that the patient will use to perform the rehabilitation exercises will be installed. The client computer will send the patient's rehabilitation session data to the Server computer, which will be accessible by a therapist to assess the patient's evolution(Hoda M., El Saddik A., Phan P., 2020). Communication between client and server computers will be via network. Therefore, the quality of network services is very important for the performance of remote therapy systems (Popescu et al., 2000).

Thus, when the patient performs the rehabilitation sessions using remote therapy, the patient will use the client computer to perform the exergame. This client computer will record the performance data and send it to the server computer in order to provide the therapist with the necessary information to evaluate the patient's progress (Hosseiniravandi et al., 2020) . In addition, the therapist can enter new settings for the patient's upcoming rehabilitation sessions and send them to the exergame that is installed on the client computer.

However, in recent years, this Client-Server framework has been improved and other types of framework for remote terapies were proposed. These developments have enabled the processing of exergames with advanced technologies and more robust remote therapy systems. According to Table I and Figure 2.a, we identified in the studies of this review 5 different types of remote therapy frameworks: Client-Server, Web-Based, Layers, Cloud Based e Multi users.

\section{Client-Server Framework}

This model of telerehabilitation system is the classic Client-Server: the exergame is installed on the computer (Client) of the patient's home and a software to store the patient session data is installed on another machine (Server). These two machines communicate via network protocol. The basic application of this model has improved and the type of communication between client and server computers is evolving and allowing new interactions with the user. In this framework design, the work of (Popescu et al., 2000) was one of the pioneers in introducing the concept of novel multipurpose haptic control interface. A force feedback glove for orthopaedic rehabilitation is connected to the patient's computer. This glove is an exoskeletal structure that provides forces on the patient's fingertips and contains position sensors to control an object within the exergame. Also, while wearing the rehabilitation gloves, the patient controls the system using voice commands. Data collected during the rehabilitation exercises is stored remotely at the server machine using the Internet. Also, remote consultation is allowed using a videoconferencing system. In addition, the study of (Varela-Aldás et al., 2020) improved the client-server framework for an mobile application with and immersive virtual reality application. The exergame is controlled by the Oculus Go (Oculos, 2021) which contains the inertial measurement unit to track 3 degrees of freedom of angular movement. The great differential of these two works is the possibility of inserting more than one input device for the user to control the exergame, using the basic Client-Server framework. 


\section{Web Based Framework}

The Web based framework has as main characteristic the use of Web services to enable telerehabilitation. The study of (Reinkensmeyer et al., 2002) initiated this model by inserting game therapy: users enter the system using the web, carry out a personalised programme of therapy activities and receive information on their rehabilitation progress. The system uses a joystick to control the exergames. Also, the remote therapy of (Karime et al., 2012), makes use of internet connectivity to provide a link between the patient and the therapist. The exergame provides an ankle muscle strengthening exercise using the rotation information and pressure information from the wireless wobble board as input. Furthermore, the work of (PérezMedina et al., 2019) brought the concepts of real time evaluation, flexible and modular software architecture to the Web Based Framework.

Moreover, in the study of (Zedda et al., 2020) the exergame is implemented in Unity 3D and is supported by a web application accessible from anywhere by medical staff and patients, allowing constant monitoring of rehabilitation progress. Furthermore, the work of (Postolache et al., 2021) apresenta uma inovação no modelo Web Based: o uso de Internet of Things (IoT). IoT Systems focuses on data analysis of data extracted during the training session, where patients are using wearable sensing devices to interact with the exergame (Bhatt et al., 2017; Qusay F. Hassan, 2018; Shahrestani, 2017). IoT based systems are a new model of communication between humans and things: we can have connectivity to everything, anywhere, and at any time (Agrawal \& Vieira, 2013; Tan \& Wang, 2010). The goal of IoT systems is to establish synergy between different systems and make them communicate automatically to provide important services to users (Qusay F. Hassan, 2018).

\section{Layers Based Framework}

Another framework design approach for exergames in Telerehabilitation is the concept of Layers. In this model, the telerehabilitation system is completely separated into layers: layer for management of harwdares (input devices), layer to perform the exergame and a layer for therapy management. The work of (Vourvopoulos et al., 2013) presents an architecture consisting of three main layers: hardware for device support, control panel for translation and data emulation, and Web Content for access to the rehabilitation tools. All layers are interconnected in a client-server architecture. Also, the research of (Paraskevopoulos et al., 2016) implemented the novelty about holistic nature: it includes the technology agnostic approach, as it addresses the input controllers to a separate layer. This concept allows the total customisation of the rehabilitation therapy to a higher level of fidelity and granularity, since the therapist is able to define all the parameters of each repetition of the exercise that the patient will perform with the exergame.

\section{Cloud Based Framework}

And following a new trend in technology, some cloud-based rehabilitation systems have already been proposed. Basically, these systems use cloud services to store the therapy database and the intelligent systems that control the exergames. The work of (Oliver et al., 2018) proposed an adaptive and personalized exercise. The system contains 3 main components: frontend (runs the exergame), processes (data processing and storage) and backend (cloud storage: artificial intelligence modules and data analysis). In addition, data are continuously stored on the cloud to allow real-time sessions analytics. Moreover, the study of (H.-J. Li \& Song, 2017) presented a new architecture of a cloud robotic system for upper-limb rehabilitation with multimodal interaction. This system consists of a cloud central server, several therapists as the server and patients as clients that may be distributed with patients in anywhere (home, community, etc). All patients and therapists are connected to the central server through cloud. Each client computer includes a robotic arm attached and a input device to control it. Furthermore, the work of (Oliver et al., 2018) consists of two subsystems: cognitive and inference. The cognitive 
subsystem is located on both the therapist's and patient's computer. The data collected in each rehabilitation session is sent to inference subsystem which is stored in the cloud.

\section{Multiuser Framework}

The multi-user approach, allows several patients and therapists to be connected simultaneously in the same rehabilitation session. In the work of (Triandafilou et al., 2018), stroke patients can interact with therapists in the same virtual space. The system has a central server that interacts with the patients' computers, one for each user. The server receives information from the patient computers and controls the updating of the exergame scene so that the appropriate view of the scene is shown on each patient computer. In addition, the study of (Andrade et al., 2013) proposes a framework for multipatient rehabilitation integrating robots and exergames. The architecture supports multiple rehabilitation robots that send and receive messages simultaneously. The exergame receives position and speed data from the robot and the robot receives the data representing the movement that must be performed to assist in the patient's rehabilitation.

After analyzing all the studies using the five types of remote therapy framework described above, we found that there is a natural evolution and, in some cases, a combination of the framework designs. As we have already detailed above, each of them has advantages. Howevver, the best choice of approach that should be used has to consider mainly the patient. According to Table 1, all the studies presented use some kind of device to be the input control of the exergame and, in some cases, even more than one device is required. Indeed, all exergames need an input device to control it. But it important to highlight that, depending on the device needed, it may not be affordable for purchase by all patients.

Another issue that needs to be considered is that with the increasing evolution of exergame building softwares and that, consequently, needs a great graphical interface to run it, it is necessary that the computer that will run this software has a very good configuration. Otherwise, it will not be possible to install the system or the exergame will run slowly because the computer will not have the necessary processing resources. And, we have to remember that the exergame will be installed and run on the patient's computer. So, if the patient doesn't have enough money to buy a good computer, he/she won't be able to perform a home-base rehabilitation.

Thus, a primary challenge for home based telerehabilitation is to reduce the expenses for the patient. In this sense, we would be contributing to the popularization of this type of therapy as we would be developing systems that are accessible for all patients. And the key solution to address this challenge is to take advantage of all the evolution of remote therapy frameworks and use scientific knowledge to reduce the need for high processing power in the patient's computer. And also, take advantage of the computer's native input devices (web cam, mouse, keyboard etc) to collect the data needed for the patient's rehabilitation. Thus, we would have a chance to reduce the patient's expenses with the purchase of new technological resources.

For exergames that require patient motion detection, a possible solution is to use the computer's webcam as input to capture the patient's image and implement image processing algorithms to track the motion. According to the studies of (Krishnan et al., 2015; Martins, 2016), it has been shown that it is possible to implement body movement tracking techniques. Also, the work of (Adhikari \& Stark, 2017; Semmelmann \& Weigelt, 2018) suggests that it would be possible to use the computer's webcam to track the gaze. But in this context, processing the algorithms to use the webcam as an input device for the exergame would require a high cost to the patient's computer. However, it would be possible to use, for example, the Cloud based or Layer based frameworks to process the webcam image on the server computer. And so, the patient's machine would not need to be high performance.

Moreover, on the issue of the high processing power required to run the exergame, a possible solution could be a Layer framework based on streaming technique (X. Li et al., 2021). The exergame would be installed on the server computer 
and the high processing would be in charge of it, and the patient's computer would only receive the necessary images of the game (Ghadiyaram et al., 2017). This solution could make it easier for many patients to have a telerehabilitation system at home, as it would not be necessary to spend a lot of money since the computer would not need to have such a high processing power.

The authors recognize that there are limiting factors in this survey: 1) Databases accessed: The authors searched the articles in reliable databases, but acknowledge that not all existing databases were accessed;2) Search Query: the selection of the keywords used in the searching strategy might have resulted in the exclusion of some publication.

\section{Conclusion}

We presented a review of the types of home based telerehabilitation frameworks that have already been developed. It was possible to verify the evolution and combination of the various existing models. The areas of application of rehabilitation using remote therapy are the most diverse (stroke, cognitive, upper-limb, chronick neck pain) and most systems have the possibility to expand the type of therapy.

The home based telerehabilitation, in addition to facilitating for the therapist, as he/she does not have to move to where the patient is, also facilitates and includes the patient. Many patients would not be able to attend the rehabilitation clinic as often as necessary to provide treatment. Also, in periods of pandemic, when people are isolated at home, home based telerehabilitation has a greater prominence.

In this context, with the improvement of telerehabilitation systems, which are mostly composed of well-designed exergames to improve patient engagement, it is necessary that the patient has a computer suitable for installing and running the exergame. And it is not always possible for the patient to buy or get government assistance to buy a good computer and the necessary devices to run the exergame.

One of the possible solutions to these issues is to consume as little as possible the processing of the patient's computer - so the machine would not need to have such an advanced configuration. The use of the webcam for tracking the patient's movements (body and eyes) and the execution of the exergame via streaming may be a solution worth investigating. Also, the combination of the remote therapy frameworks presented here in this review may be a new way to assist in solving these issues. These improvements may help to increase the number of patients who have access to home-based telerehabilitation.

Finally, we hope that the information presented in this review can help in the updating and development of new guidelines and solutions for future researches in the remote therapies. For future studies, it is important to investigate new combinations of framework design to make home-based telerehabilitation more accessible for all people, to research new methods of cheaper input devices for exergames and to investigate techniques that can reduce the processing of exergames while maintaining graphic quality.

\section{Acknowledgments}

This study was financed in part by the Coordenação de Aperfeiçoamento de Pessoal de Nível Superior - Brasil (CAPES). Finance Code 001.

\section{References}

Adhikari, S., \& Stark, D. E. (2017). Video-based eye tracking for neuropsychiatric assessment. Ann. N.Y. Acad. Sci, 1387, 145-152. https://doi.org/10.1111/nyas.13305

Afyouni, I., Murad, A., \& Einea, A. (2020). Adaptive Rehabilitation Bots in Serious Games. Sensors, 20(7037). https://doi.org/doi:10.3390/s20247037

Agrawal, S., \& Vieira, D. (2013). A survey on Internet of Things: um estudo sobre Internet das Coisas. ABAKÓS, 1(2), 78-95. 
Amorim, P., Santos, B. S., Dias, P., Silva, S., \& Martins, H. (2020). Serious Games for Stroke Telerehabilitaton of Upper Limb - a Review for Future Research. International Journal of Telerehabilitation, 12(2), 1-12. https://doi.org/10.5195/ijt.2020.6326

Andrade, K. de O., Fernandes, G., Junior, J. M., Roma, V. C., Joaquim, R. C., \& Caurin, G. A. P. (2013). Rehabilitation robotics and serious games: An initial architecture for simultaneous players. Biosignals and Biorobotics Conference (BRC), 2013 ISSNIP. https://doi.org/10.1109/BRC.2013.6487455

Bamidis, P. D., Konstantinidis, E., Billis, A. S., \& Sioundas, A. (2015). Reviewing Home Based Assistive Technologies. IGI Global. https://doi.org/10.4018/978-1-4666-8234-4.ch017

Bhatt, C., Dey, N., \& Ashour, A. S. (2017). Internet of Things and Big Data Technologies for Next Generation Healthcare. Springer. https://doi.org/10.1007/978-3-319-49736-5

Chena, Y., Abelb, K. T., Janecekc, J. T., Chenb, Y., Zhengb, K., \& Cramerd, S. C. (2019). Home-based technologies for stroke rehabilitation: A systematic review. International Journal of Medical Informatics, 123, 11-22. https://doi.org/https://doi.org/10.1016/j.ijmedinf.2018.12.001

Deponti, D., Maggiorini, D., \& Palazzi, C. E. (2011). Smartphone's physiatric serious game. 2011 IEEE 1st International Conference on Serious Games and Applications for Health (SeGAH). https://doi.org/10.1109/SeGAH.2011.6165434

Ghadiyaram, D., Pan, J., \& Bovik, A. C. (2017). Learning a Continuous-Time Streaming Video QoE Model. IEEE TRANSACTIONS ON IMAGE PROCESSING. https://doi.org/10.1109/TIP.2018.2790347,

Hoda M., El Saddik A., Phan P., W. E. (2020). Haptics in Rehabilitation, Exergames and Health. https://doi.org/10.1007/978-3-030-34230-2_5. https://doi.org/https://doi.org/10.1007/978-3-030-34230-2_5

Hosseiniravandi, M., Kahlaee, A. H., Karim, H., Ghamkhar, L., \& Safdari, R. (2020). Home-based telerehabilitation software systems for remote supervising: a systematic review. Int J Technol Assess Health Care, 36(2), 113-125. https://doi.org/10.1017/S0266462320000021

Karime, A., Al-Osman, H., Alja'am, J. M., Gueaieb, W., \& Saddik, A. El. (2012). Tele-Wobble: A Telerehabilitation Wobble Board for Lower Extremity Therapy. IEEE TRANSACTIONS ON INSTRUMENTATION AND MEASUREMENT, 61(7), 1816-1824.

Krishnan, C., Washabaugh, E. P., \& Seetharaman, Y. (2015). A low cost real-time motion tracking approach using webcam technology. $J$ Biomech, 48(3), 544-548. https://doi.org/10.1016/j.jbiomech.2014.11.048

Li, H.-J., \& Song, A.-G. (2017). Architectural Design of a Cloud Robotic System for Upper-Limb Rehabilitation with Multimodal Interaction. Journal Of Computer Science And Technology, 32(2), 258-268. https://doi.org/10.1007/s11390-017- 1720-4

Li, X., Darwich, M., Salehi, M. A., \& Bayoumi, M. (2021). A survey on cloud-based video streaming services. In Advances in Computer. Elsevier. https://doi.org/doi.org/10.1016/bs.adcom.2021.01.003

Mantovani, E., Zucchella, C., Bottiroli, S., Federico, A., Giugno, R., Sandrini, G., Chiamulera, C., \& Tamburin, S. (2020). Telemedicine and Virtual Reality for Cognitive Rehabilitation: A Roadmap for the COVID-19 Pandemic. Frontiers in Neurology, 1-18. https://doi.org/10.3389/fneur.2020.00926

Martins, J. B. (2016). Webcam motion detection and tracking interfaces for immersive embodied experiences. Técnico Lisboa.

Matamala-Gomez, M., Maisto, M., Montana, J. I., Mavrodiev, P. A., Baglio, F., Rossetto, F., Mantovani, F., Riva, G., \& Realdon, O. (2020). The Role of Engagement in Teleneurorehabilitation: A Systematic Review. Frontiers in Neurology, 1-23. https://doi.org/10.3389/fneur.2020.00354

Microsoft. (n.d.). Azure Kinect DK. https://azure.microsoft.com/pt-br/services/kinect-dk/

Moher;, D., Liberati;, A., Tetzlaff;, J., \& G, D. (2009). Preferred reportingitems for systematic reviews and meta-analyses: the PRISMA statement. BMJ, 339(b2535), 1-8. https://doi.org/http://dx.doi.org/10.1136/bmj.b2535.

Norouzi-Gheidari, N., Hernandez, A., Archambault, P. S., Higgins, J., Poissant, L., \& Kairy, D. (2019). Feasibility, Safety and Efficacy of a Virtual Reality Exergame System to Supplement Upper Extremity Rehabilitation Post-Stroke: A Pilot Randomized Clinical Trial and Proof of Principle. International Journal of Environmental Research and Public Health, 17(1). https://doi.org/10.3390/ijerph17010113

Oculos. (2021). Oculos Go. https://www.oculus.com/

Oliver, M., Teruel, M. A., Molina, J. P., Romero-Ayuso, D., \& González, P. (2018). Ambient Intelligence Environment for Home Cognitive Telerehabilitation. Sensors, 18, 1-30. https://doi.org/10.3390/s18113671

Paraskevopoulos, I. T., Tsekleves, E., Warland, A., \& Kilbride, C. (2016). Virtual Reality-based holistic framework: a tool for participatory development of customised playful therapy sessions for motor rehabilitation. 2016 8th International Conference on Games and Virtual Worlds for Serious Applications (VSGAMES). https://doi.org/10.1109/VS-GAMES.2016.7590378

Pérez-Medina, J.-L., Jimenes-Vargas, K. B., Leconte, L., Villarreal, S., Rybarczyk, Y., \& Vanderdonckt, J. (2019). ePHoRt: Towards a Reference Architecture for Tele-Rehabilitation Systems. IEEE Access, 1-18. https://doi.org/10.1109/ACCESS.2019.2927461

Popescu, V. G., Burdea, G. C., Bouzit, M., \& Hentz, V. R. (2000). A Virtual-Reality-Based Telerehabilitation System with Force Feedback. IEEE Transactions On Information Technology In Biomedicine, 4(1), 45-51.

Postolache, O., Hemanth, D. J., Alexandre, R., Gupta, D., \& Geman, O. (2021). Remote Monitoring of Physical Rehabilitation of Stroke Patients using IoT and Virtual Reality. IEEE Journal on Selected Areas in Communications, 3(2), 562-573. https://doi.org/10.1109/JSAC.2020.3020600

Qusay F. Hassan. (2018). Internet of Things A to Z Technologies and Applications. IEEE press Wiley. 
Research, Society and Development, v. 10, n. 6, e4910615489, 2021

(CC BY 4.0) | ISSN 2525-3409 | DOI: http://dx.doi.org/10.33448/rsd-v10i6.15489

Rego, P. A., Moreira, P. M., Science, C., \& Reis, L. P. (2014). A Serious Games Framework for Health Rehabilitation. International Journal of Healthcare Information Systems and Informatics, 9(3), 1-21. https://doi.org/10.4018/ijhisi.2014070101

Reinkensmeyer, D. J., Pang, C. T., Nessler, J. A., \& Painter, C. C. (2002). Web-Based Telerehabilitation for the Upper Extremity After Stroke. IEEE Transactions On Neural Systems And Rehabilitation Engineering, 10(2), 102-108.

Sardi, L., Idri, A., \& Fernández-Alemán, J. L. (2017). A systematic review of gamification in e-Health. Journal of Biomedical Informatics, 31-48. https://doi.org/http://dx.doi.org/10.1016/j.jbi.2017.05.011

Semmelmann, K., \& Weigelt, S. (2018). Online webcam-based eye tracking in cognitive science: A first look. Behav Res, 50, 451-465. https://doi.org/10.3758/s13428-017-0913-7

Shahrestani, S. (2017). Internet of Things and Smart Environments Assistive Technologies for Disability, Dementia, and Aging. Springer. https://doi.org/10.1007/978-3-319-60164-9

Silva, T. D. da, Silva, P. L. da, Valenzuela, E. de J., Dias, E. D., Simcsik, A. O., \& Carvalho, M. G. de. (2021). Serious Game Platform as a Possibility for Home-Based Telerehabilitation for Individuals With Cerebral Palsy During COVID-19 Quarantine - A Cross-Sectional Pilot Study. Frontiers in Psychology, 12(622678), 1-15. https://doi.org/doi: 10.3389/fpsyg.2021.622678

Tan, L., \& Wang, N. (2010). Future Internet: The Internet of Things. 3rd International Conference on Advanced Computer Theory and Engineering(ICACTE), $376-380$.

Triandafilou, K. M., Tsoupikova, D., Barry, A. J., Thielbar, K. N., Stoykov, N., \& Kamper, D. G. (2018). Development of a 3D, networked multiuser virtual reality environment for home therapy after stroke. Journal of NeuroEngineering and Rehabilitation, 15(88), 1-13. https://doi.org/https://doi.org/10.1186/s12984-018-0429-0

Varela-Aldás, J., Palacios-Navarro, G., Amariglio, R., \& García-Magariño, I. (2020). Head-Mounted Display-Based Application for Cognitive Training. Sensors, 20(6052), 1-22. https://doi.org/10.3390/s20226552

Vourvopoulos, A., Faria, A. L., Cameirão, M. S., \& Badia, S. B. i. (2013). RehabNet: A Distributed Architecture for Motor and Cognitive NeuroRehabilitation -Understanding the Human Brain through Virtual Environment Interaction. 2013 IEEE 15th International Conference on E-Health Networking, Applications and Services (Healthcom 2013), 454-459. https://doi.org/10.1109/HealthCom.2013.6720719

Zedda, A., Gusai, E., Caruso, M., Bertuletti, S., Baldazzi, G., Spanu, S., Riboni, D., Pibiri, A., Monticone, M., Cereatti, A., \& Pani, D. (2020). DoMoMEA: a Home-Based Telerehabilitation System for Stroke Patients. Annu Int Conf IEEE Eng Med Biol Soc, 5773-5776. https://doi.org/doi: 10.1109/EMBC44109.2020.9175742 